\title{
Verão no aquário e Fazes-me falta: considerações sobre a escrita em Lygia Fagundes Telles e Inês Pedrosa
}

\author{
Verão no aquário and Fazes-me falta: considerations about the \\ writing in the works of Lygia Fagundes Telles and Inês Pedrosa
}

\author{
Licilange Gomes Alves* \\ licilangealves88@gmail.com \\ Universidade Federal do Ceará
}

RESUMO: Este artigo objetiva fazer dialogar os romances Verão no aquário, de Lygia Fagundes Telles, e Fazes-me falta, de Inês Pedrosa, na perspectiva da linguagem literária. Parte-se da hipótese de que esta categoria se apresenta como errante e impotente para esclarecer o que diz, constatação que não é vista como problemática, apenas como composição do estilo peculiar das escritoras. Segundo a crítica, esses romances são significativos na consagração de ambas as autoras, consideração que se justifica, principalmente, pela irreverência da linguagem neles trabalhada. A análise foi fundamentada em contribuições voltadas ao estudo da literatura contemporânea, em especial, Maurice Blanchot $(1997 ; 1987)$ e Roland Barthes (1984; 2011). Para compreender as acepções feitas pela crítica, foram consultados, dentre outros, os trabalhos de Diana Navas e Telma Ventura (2018); Sônia Régis (1998). Constatou-se que a linguagem, nessas obras, é entrelaçada à ideia de morte, tema presente nos dois enredos e que comunga com a escritura das autoras.

PALAVRAS-CHAVE: Escrita. Ausências. Morte. Verão no aquário. Fazes-me falta.

\begin{abstract}
This article aims to propose a dialogue between the novels Verão no Aquário, by Lygia Fagundes Telles, and Fazes-me Falta, by Inês Pedrosa, from the perspective of literary language. It is hypothesized that this category presents itself as wandering and powerless to clarify what it says, an observation that is not seen as problematic, only as a composition of the writers' peculiar style. In this way, according to the critics, these novels are significant in the consecration of both, a consideration that is mainly justified by the irreverence of the language worked on them. The analysis was based on contributions aimed at the study of contemporary literature, especially Maurice Blanchot $(1997 ; 1987)$ and Roland Barthes $(1984 ; 2011)$. To understand the meanings made by the critics, the works of Diana Navas, Telma Ventura (2018) and Sonia Régis (1998) were consulted, among others. Thus, it was found that language, in these novels, is intertwined with the idea of death, a theme present in the both plots and that it communes with the writing of the authors.
\end{abstract}

\footnotetext{
* Graduada em Letras Língua Portuguesa pela Universidade Estadual Vale do Acaraú - UEVA. Mestra pelo Programa de Pós-Graduação em Letras - PPGL em Estudos do discurso e do texto pela Universidade do Estado do Rio Grande do Norte (UERN). Atualmente, é doutoranda em Literatura Comparada pelo Programa de Pós-Graduação em Letras (PPGLetras) pela Universidade Federal do Ceará (UFC). É bolsista FUNCAP, desenvolvendo pesquisas na área de Letras, com ênfase em Literatura.
} 
KEYWORDS: Writing. Absence. Death. Verão no aquário. Fazes-me falta.

\section{Introdução}

As produções de Lygia Fagundes Telles e Inês Pedrosa parecem comungar da defesa de que a literatura é expressão cultural de uma nação ao trabalharem questões que singularizam os contextos do Brasil e de Portugal. Ambos os países exercem entrelaçamentos, especialmente no tocante ao tecer de suas literaturas.

No bojo dessas ideais iniciais, esse estudo objetiva analisar a linguagem trabalhada no corpus escolhido, composto pelos romances Verão no aquário (1964), de Lygia Fagundes Telles, e Fazes-me falta (2002), da escritora portuguesa Inês Pedrosa.

São autoras de vastas produções ficcionais que apresentam aproximações, tanto do ponto de vista temático quanto linguístico. Os enredos dos dois romances são revestidos por um caráter fúnebre e construídos por meio de uma linguagem vazia, que burla a tradicional intriga linear com sintaxe regular para se fundir ao silêncio que a própria morte incita. Elementos como ausências, mistérios entre vida e morte, o silêncio que a escuridão da noite abriga, relações entre morte, noite e linguagem perpassam os livros escolhidos para o estudo e comprovam pontos de encontro entre os dois.

\section{Lygia Fagundes Telles e Inês Pedrosa: algumas considerações sobre as duas escritoras}

Lygia Fagundes Telles possui um expressivo público de leitores e também de pesquisadores. Autora de produção galardoada com vários prêmios literários, Lygia escreveu textos que apresentam, a cada nova leitura, outros olhares sobre os mesmos temas, entre eles, loucura, solidão, medo, amor, inclusive sobre a morte e a linguagem literária.

O delineamento de suas personagens raramente é feito com objetividade, haja vista sua preferência pela introspecção. Sônia Régis (1998) aponta como uma das características da obra lygiana o aprisionamento do leitor de modo que esse se limita à estreita linha entre realidade e representação. Segundo essa pesquisadora, uma das grandes inquietudes da ficcionista é abordar o mistério existente na palavra de modo a formar uma atmosfera simbólica inédita. 
A obra lygiana é riquíssima quanto à abordagem de temas, dentre eles, a morte. Não é a partir de Verão no aquário que essa temática desponta em seus textos. Outro exemplo da presença da morte e de questões metalinguísticas em Lygia está em Ciranda de pedra, publicado em 1954, cujo enredo é dividido em duas partes. Na primeira, a protagonista Virgínia é uma menina que vive uma infância solitária e triste na casa da mãe e do pai biológico. Na segunda parte, ela retorna do colégio interno para a casa do pai postiço e descobre que seu verdadeiro pai se suicidou e a mãe morreu. A partir de então, o caos de suas problemáticas existenciais se torna mais potencializado diante dessas perdas. Também no romance As meninas, a morte exerce um dos papéis centrais na trama, silenciando uma das personagens cujo direito de fala foi sempre interceptado.

Quanto a Inês Pedrosa, a morte também é um tema bem presente em sua produção, como mostra logo em seu primeiro romance, A instrução dos amantes, publicado em 1992, o qual já inicia com o funeral de Mariana, cuja morte é um enigma, pois não fica explicado se foi suicídio ou acidente.

Seu segundo romance, Nas tuas mãos, publicado em 1997, após o fim do Governo Salazarista, levanta vários pontos relacionados a esse período, especialmente sob a perspectiva de Camila. Esta conhece Xavier, um guerrilheiro moçambicano que morre durante uma guerra e deixa Camila grávida de Natália, a qual compõe a terceira geração da tríade.

Cada mulher representada nessas personagens remete a uma geração diferente, sendo, portanto, três gerações - a avó, a filha e a neta - trazendo percepções de diferentes períodos do contexto histórico de Portugal. A morte da avó servirá para nortear a vida das suas duas gerações posteriores, da filha e da neta. Essa morte ficará reverberando por toda a narrativa através do diário que a avó deixou e será conhecido pela filha Camila e a neta, Natália.

Após a perda de várias pessoas queridas, Inês Pedrosa confessa ter se tornado obcecada pela temática da morte, foi quando lhe surgiu o enredo de uma mulher jovem, morta, e de seu amigo, homem mais velho. Assim, veio ao mundo Fazes-me falta, um livro que evoca ausências e silêncios já desde o título.

Fazes-me falta é o único livro da escritora escrito inteiramente à mão. Lançado na Bienal Internacional do Livro do Rio de Janeiro em 2003, Fazes-me falta teve sua escrita iniciada em 1999 em um momento 
paradoxal da vida da autora: o nascimento da filha, a morte de seu pai e de outras pessoas próximas [...]. (LAGUARDIA, 2007, p. 17)

\section{Verão no aquário e Fazes-me falta: o (des)tecer da escrita em Lygia Fagundes Telles e Inês Pedrosa}

Em seus textos, Lygia e Inês costumam levantar considerações acerca de questões metaliterárias, incitando reflexões sobre o seu objeto de trabalho: a linguagem literária. Ambas as escritoras são consideradas, para a presente análise, transgressoras no tocante ao modo como constroem suas narrativas por transcender os limites da linguagem através de discursos que permeiam o indizível. Referindo-se à obra lygiana, Carlos Magno Gomes (2017, p. 558) considera que

[...] o jogo metanarrativo faz parte das opções estéticas de Lygia Fagundes Telles. Por exemplo, em Ciranda de Pedra (1954), temos os quadros de Otávia, irmã da protagonista Virgínia, funcionando como referência à desestruturação familiar; em Verão no aquário (1963), há os comentários críticos de Raíza, a protagonista transgressora, acerca dos romances de Patrícia, sua mãe. Tais críticas mostram uma repulsa ao romance tradicional de formação feminina que a mãe escreve; em As meninas (1973), identificamos o mal-estar da literatura em Lia, uma feminista guerrilheira, que abandona a escrita de um romance engajado por se sentir traída pela subjetividade da escrita literária; já em As horas nuas (1989), a metanarração pode ser identificada pela construção paródica da biografia de Rosa, uma atriz decadente que faz uma escrita teatral de suas memórias.

Conforme o crítico, a metanarratividade é uma das características da escrita lygiana. A escritora prova, assim, que a linguagem literária pode falar sobre aspectos, como a sociedade na qual é produzida, o sujeito que a produz e os pontos de vista perspectivados em suas personagens, mas também fala sobre seu próprio tecer, conforme se vê em Verão no aquário. Esse apresenta em seu enredo os medos e as angústias da personagem Raíza, que sofre um problemático processo de amadurecimento por vários motivos, em especial pelo fato de ter perdido o pai precocemente para o alcoolismo e também por se sentir rejeitada pela própria mãe, com a qual ela passa a disputar o amor de André, sujeito de quem a menina desconfia ser o amante de Patrícia, sua mãe.

Narrados em primeira pessoa, os acontecimentos desse romance chegam ao leitor pela voz de Raíza, permitindo-lhe ter um maior conhecimento a respeito do que se passa com a personagem. Constantemente, ela tem devaneios que a fazem reviver 
a presença de seu falecido pai; assim, suas ações estão quase sempre marcadas pelas lembranças deste, trazendo saudade e muita melancolia, sentimentos que ecoam por toda a sua trajetória na narrativa.

Nota-se, logo nas primeiras linhas do romance, que a teia ficcional é tematizada pela morte, que, entretanto, não é um acontecimento aceito de forma passiva pelos personagens, assim como geralmente ocorre aos personagens lygianos: "[...] suas personagens estão tentando negar a morte. Não por acaso, a autora cita muito a frase: 'A arte é a negação da morte'. Ou seja, a morte está aí para ser evitada, confrontada, nunca aceita de peito aberto" (LUCENA, 2014, p. 55).

A morte é um tema que sempre intrigou a humanidade. Os efeitos provocados por ela, por meio do luto, deixam sem palavras aqueles que ficam sem saber o que dizer diante da perda de quem se amou. A morte de alguém pressupõe o desvio do fluxo normal da vida, de quem fica e de quem vai.

É nessa perspectiva de ausências que se constrói, também, o romance Fazes-me falta, publicado em 2002, sendo parte da produção de uma autora cuja obra se situa no panorama da Literatura Portuguesa contemporânea. A narração de cada capítulo é intercalada pela fala de duas personagens: uma mulher morta e um homem vivo, ambos sem nome. Tudo é narrado entre saudades e (des)amores. $O$ relacionamento que houve entre essas duas personagens é desconhecido, deduz-se que eram grandes amigos, porém, em certos momentos, deixa-se entender que ambos viveram um relacionamento amoroso. Trata-se de uma relação indefinida, assim como é o mistério da morte, que não se compreende, mas se sente por meio do luto.

Roland Barthes (1984, p. 113), ao relatar sobre o luto vivenciado pela perda de sua mãe, afirma o seguinte: "Dizem que o luto, por seu trabalho progressivo, apaga lentamente a dor; eu não podia, não posso acreditar nisso; pois, para mim, o Tempo elimina a emoção da perda (não choro), isso é tudo". Na visão barthesiana, o luto não passa e nem é amenizado com o passar do tempo. O luto evoca no enlutado a sensação de também estar morto, sem desejo pela continuidade da vida e de tudo aquilo que se constitua como natural a ela. Ora, mas a morte e seu consequente estado de luto naquele que fica não seriam também acontecimentos naturais da vida?

A morte seria, talvez, uma das poucas certezas que se tem, logo, deveria ser encarada com naturalidade, porém não o é, provocando um caos de sentimentos em cada indivíduo. Para Raíza, de Verão no aquário, a morte está muito relacionada à 
solidão: "[...] os mortos são solitários! Meu Deus, como são solitários" (TELLES, 1998, p. 13). Já a prima, Marfa, sente aversão, “-Tenho nojo de mortos, compreende? Por mais que se ame um morto, é preciso prender a respiração para beijá-lo" (TELLES, 1998, p. 13). A morte é, assim, vista como um fato que, embora comum, causa surpresa, ou repulsa.

Sobre Fazes-me falta, sua linguagem é tecida com bastante lirismo, característica que justifica o romance ser considerado, por Navas e Ventura (2018), prosa poética. As pesquisadoras afirmam que Fazes-me falta está amparado nessa hibridização de gêneros; por isso, transcende os limites da linguagem por meio de um discurso que atinge o indizível.

Anjo que tardas, minha lotaria, dá-me as tuas asas que eu dou-te alegria. Anjo sem casa nem sabedoria, balda-te ao céu, faz-me companhia. Anjo fugido, de cabeça esguia, pousa no meu colo e dizme "bom dia". Anjo enganado, cor da minha vida, volta para o meu lado ou dá-me uma saída. Anjo do escuro, pássaro sem medo, leva as minhas penas, dá-me o teu segredo (PEDROSA, 2003, p. 75).

O excerto demonstra bem a fusão das duas modalidades textuais supramencionadas, prosa e poesia. Há uma musicalidade expressa pelas rimas "lotaria”, "alegria”, "sabedoria”, "companhia”," esguia”, "dia”, "enganado”, "lado” "vida”," "saída", "medo", "segredo" -, realçando o tom lírico dessa prosa. Destarte, nota-se um monólogo proferido pelo homem, compondo um curtíssimo capítulo em que esse faz uma súplica por companhia para fugir da solidão e do tédio.

Além da poeticidade, a escrita, nesse livro, é caracterizada pela presença de um aspecto comum no romance contemporâneo: a fragmentação. É relevante perceber a linguagem fragmentada e cética constituída de modo similar ao mundo criticado pelas personagens, aos sujeitos habitantes dele e ao enredo inusitado. É como se tudo isso fosse colocado em xeque porque acontece em espaços movediços que não oferecem estabilidade para quem vive nele. Tal perspectiva é apresentada por meio de um elemento instável que, assim como a morte, nada diz: a linguagem.

A linguagem do texto pedrosino não é linear, porém, talvez se o fosse, ela não daria conta de falar por essas personagens tão densas, marcadas por incertezas e lacunas. Os dizeres ficam no vazio, apenas no campo das possibilidades. Paradoxalmente, tal linguagem é empregada apenas para dizer que ela nada diz e reside na incompletude, uma vez que todas as situações chegam ao leitor de modo 
duvidoso e incompleto. Assim, quanto mais o leitor cumpre seu papel de juntar os dados expressos para ter uma compreensão do todo, mais ele se depara com o vácuo dos discursos das personagens, isso porque a linguagem é impotente e não pode dar conta de dizer tudo.

Há sempre algo em suspenso, conforme sugere este trecho de Pedrosa: "Mas também a amizade se mostrou vulnerável ao tédio e à decepção. Tudo o que tocamos se desfaz. Depois fica-nos o vício da decomposição, o perfume intoxicante das coisas mortas" (PEDROSA, 2003, p. 56). A tentativa de adentrar à literatura para compreendê-la faz com que esta seja dissipada, ficando apenas o espaço vago. Em consonância com estas considerações, Maurice Blanchot (1997) associa a ideia de morte à arte afirmando que tanto esta quanto aquela são espaços em que os dizeres não podem ser explicados claramente.

$\mathrm{Na}$ concepção blanchotiana, o próprio ato de compreender está ligado à ideia de morte, visto que, ao buscar a compreensão de uma obra, o sujeito a mata; a literatura não tem direito à morte, não devendo, portanto, ser compreendida. Tanto a literatura, quanto o estar a morrer e a noite tendem para o obscuro, aquilo que é incompreensível. É interessante observar as várias menções feitas à noite no romance pedrosino:

Os tios que tomaram conta de mim diziam-me que eles estavam no céu a velar pelo meu futuro, e eu enfurecia-me com esses pais mudos que me deixavam na solidão da noite interrogando as estrelas. Nunca os ouvi, como tu não ouves agora o que te digo. Mas o sorriso de Deus tocou-me, provando, na sua oscilação, que eles estavam lá, algures, no negro. E parecia-me que a graça da existência consistia em procurar vozes na noite - uma noite cuja cauda se arrasta pelo fundo do mar e pelo interior da terra, uma noite que o vapor branco do sol apenas abre um pouco mais. Assim me apaixonei pelos livros - pela noite que neles nos invade, quando os abrimos, pela noite que neles nos resiste, depois de lidos, relidos e fechados. Pela noite que prossegue, incansável, entre as palavras, as palavras sem dono, escritas da ausência para a ausência (PEDROSA, 2003, p. 50).

Semelhante à morte, que institui faltas, é a escrita literária, que se constitui no limiar da ausência, esta percebida nos romances em tela: no livro pedrosino, sua linguagem aparece ligada ao inacabado. $\mathrm{Na}$ citação acima, o narrador, no caso, a mulher morta, lamenta a ausência dos pais mudos, o que provoca a solidão da noite. Essa ausência de fala é referida em várias situações: quanto aos pais ("pais mudos"), ao homem vivo com quem, possivelmente, ela fala ("tu não ouves"), na solidão que 
ela diz ter sentido durante o tempo em que era viva. Após a morte dos pais, é criada pelos tios.

A mulher diz que os pais estavam no "negro", ou seja, no obscuro, aludindo à noite. Também fala da procura de vozes pela noite, logo, são vozes que habitam o silêncio da escuridão. Ela cita uma noite que há nos livros e permanece neles mesmo após serem lidos. Por fim, afirma que a noite segue entre palavras sem dono e escritas a partir do nada, isto é, da "ausência para a ausência".

Também no romance lygiano, a escuridão da noite é associada ao indizível, àquilo que é obscuro: "Na escuridão do quarto, só a porta tinha o contorno marcado pela frincha de luz que se infiltrava por baixo: era como a tampa do enorme caixão de um enterrado vivo, acordando com a noite ao redor" (TELLES, 1998, p. 07). Nesse trecho, a personagem Raíza encontra-se em mais um de seus constantes devaneios, fazendo alusão a elementos como noite e funeral. Para Blanchot (1987, p. 163), "na noite, reside a ausência, a escuridão, a falta de clareza, o silêncio. [...] aí se realiza e se cumpre a palavra na profundidade silenciosa que a garante como o seu sentido".

Destarte, é notável que, tanto nos textos pedrosino e lygiano, quanto no pensamento do estudioso francês, a noite é representada como uma falta, algo cuja visibilidade não se alcança, dada a escuridão. Em ambos, há uma relação com a linguagem literária, feita de palavras, sentidos e ausências.

No enredo lygiano, semelhante ao pedrosino em relação ao papel da ausência, nota-se que esta evoca mistérios, sendo envolvida por uma atmosfera que não permite ser compreendida com clareza; é um acontecimento de significado obscuro, assemelhando-se à falta de clareza da noite com a das palavras. A morte impõe o silêncio, assim como a linguagem que nada tem a dizer e, portanto, também habita o silêncio, como considera Barthes (1984, p. 138): "nada a dizer da morte de quem eu mais amo, nada a dizer de sua foto, que contemplo sem jamais poder aprofundá-la, transformá-la [...] não tenho outro recurso que não essa ironia: falar do nada a dizer".

A peculiaridade da linguagem nos romances pedrosino e lygiano provoca no leitor a impressão de haver erros na pontuação e na sintaxe, constantes truncamentos e uma incompletude nas frases. Seriam "escritas gagas", segundo Gilles Deleuze (1997), que aplica o termo a alguns escritores, no caso, apenas os ditos bons. Para o filósofo, escritores "gagos" estão entre os mais criativos. Observe-se o trecho pedrosino a seguir: 
Estás a ver porque é que eu preferi desistir dessa nossa ideia infantil de escrever romances? Já há tantos, hoje - e são tão parecidos com a mentira hiper-realista da realidade. Já há tantos, meu querido - ao menos nunca foste nenhum Sousa para mim. Tu-que-fumas. Meu querido. Velhinho. Bebé. Cabrão. Bebé é que não suportavas que eu te chamasse - e por isso te chamava tanto. O teu nome já estava demasiado gasto quanto eu te conheci. Demasiadas mulheres, demasiados códigos secretos demasiadas vezes arrombados (PEDROSA, 2003, p. 89-90).

O fragmento inicia com uma pergunta da mulher para o homem, dando a entender que se trata de um diálogo, entretanto, pelo modo como as frases vão sendo postas, percebe-se que não há uma conversa em que perguntas são feitas e respondidas simultaneamente. Há criação de expressões (Tu-que-fumas), constantes períodos curtos, que, a princípio, deduz-se, são a sequência daquilo que a personagem vem dizendo, mas a inserção de vários finais compromete a estrutura frasal, parecendo conter problemas de coesão. Estes aparentes erros caracterizam o que se chama aqui de "escrita errante".

De início, pode parecer estranho o porquê de um possível defeito - a "gagueira" - ser tão bem visto por Deleuze. Para o francês, o escritor se torna "gago" em sua própria língua, fazendo-a gaguejar e habitar o espaço da errância. Segundo as propostas literárias do século $X X$, ter estilo não é mais uma característica daquele que escreve corretamente - segundo os parâmetros da gramática normativa - e sim daquele que mais se aproxima de uma criação.

Destarte, o estilo configura-se como uma transgressão às normas tradicionais, "[...] um grande escritor é sempre estrangeiro na sua própria língua" (DELEUZE, 1997, p. 124). Os bons escritores fazem a língua gaguejar e essa gagueira revela uma singularidade na linguagem do escritor.

O gago é um sujeito que, em sua linguagem defeituosa, repete, faz retomadas de falas já ditas e se esforça para conseguir dizer algo. Na citação acima, por exemplo, é possível notar indícios dessa gagueira pelas repetições e frases entrecortadas com pontuações que sugerem uma inconclusão no pensamento das personagens.

Nas escritas pedrosina e lygiana, há um esforço por meio de palavras e efeitos que geram possibilidades e expectativas, mas que não se concretizam, ficando a critério do leitor fazê-lo. São escritas aparentemente sem coesão nem coerência, exigindo participação do leitor para construir seus sentidos; há um esforço feito para dizer e não para se fazer entendido. 
É possível afirmar que são escritas rizomáticas, palavra derivada de rizoma, metáfora botânica desenvolvida por Gilles Deleuze e Félix Guattari (2011). Ambientando o termo ao contexto da linguagem em estudo, considera-se que a grama se assemelha à língua, fazendo desta um rizoma. Diferentemente de outros vegetais, o rizoma cresce em sentido horizontal, ficando defeituoso. Entretanto, no caso dos grandes escritores, esses "defeitos" Ihes são próprios, não havendo preocupação de "falar bem" para serem aceitos.

Para estes filósofos, o rizoma é transgressor em relação ao pensamento linear, uma vez que se espalha por múltiplas direções indefinidas. Ele se abre, esparramando-se por vários caminhos por meio de suas linhas de fuga ${ }^{1}$. Característica semelhante é perceptível nas escritas das autoras em questão: ao iniciar a leitura, espera-se linearidade e clareza nas ideias apresentadas, entretanto, não é isso que se nota, como é possível atestar neste trecho de Fazes-me falta:

Estou sozinho. Sozinho com o coração em bocados espalhados pelas tuas imagens. Já não posso oferecer-te o meu coração numa salva de prata. Alguma vez o quis? Alguma vez o quiseste? Dava-me agora jeito um deus qualquer para moço de recados. Um deus que te afagasse os cabelos e me recordasse como eram macios. Um deus que me libertasse desta imagem fixa do teu corpo encaixotado. Logo $\mathrm{tu}$, que tantas vezes te rias daquilo a que chamavas o meu "encaixotamento compulsivo": - Um dia chego cá e encontro-te no meio dessa papelada, morto de cansaço, pronto a encaixotar. Olha, eu é que não te empacoto - ganhei medo a mortos (PEDROSA, 2003, p. 9).

Esta citação consta no início do capítulo que abre o livro, narrado em primeira pessoa; nela, é explicitada a ausência pela solidão que o narrador diz sentir em razão da morte da mulher, a quem ele faz indagações. Tais dúvidas ficam no vazio, suspensas, uma vez que a pessoa a quem ele se dirige não está mais no mesmo plano terreno para que possam desenvolver uma conversa convencional. Parece mais tratar-se de divagações, ou pensamentos aleatórios, ditos apenas para quem os narra, e perguntas que não esperam respostas.

Identifica-se, no trecho, uma forma rizomática de escrita porque não há uma linearidade no que está sendo dito, ou apenas refletido. Uma possível fala da mulher é lançada no meio destas divagações que o homem faz. Tais divagações também são

\footnotetext{
1 Termo trabalhado por Gilles Deleuze e Félix Guattari em Mil Platôs para se referir aos desvios feitos pelo rizoma para escapar da linearidade.
} 
entrecortadas com questionamentos que ele lança aleatoriamente, sem esperar retorno.

Os travessões remetem a um diálogo, mas, como se vê, não é uma conversa entre duas pessoas, logo não pode ser, de fato, um diálogo, pelo menos não no momento presente em que estas situações estão sendo contadas, mas, talvez o foi em um passado quando a mulher era viva. Os trechos iniciados por travessões corresponderiam às falas dela. Desse modo, é mais coerente pensar que são rememorações do homem em razão da saudade deixada pela mulher.

A escrita das referidas autoras exige que o leitor vá além da superfície da leitura, querer ler o que está além do legível, do explícito. A escrita pedrosina incita escavar a superfície do texto, ir além do que está aparentemente dito. Nos romances em estudo, os acontecimentos se passam no campo das incertezas: em Fazes-me falta, não se sabe se são fatos, quase tudo é recontado na fala de ambas as personagens por meio de rememorações, que promovem o limiar entre real e irreal, uma vez que a própria memória transita na esfera da ficção. Dessa forma, memória e ficção são entrecruzadas em Fazes-me falta, assim como as vozes narrativas.

Sobre a escrita de Inês Pedrosa, Navas e Ventura (2018) consideram-na semelhante a uma tessitura composicional em renda porque é como se apresentasse brechas, lacunas, construindo - ou desconstruindo? - uma escrita fragmentada, embora seus dizeres sejam proferidos por meio de uma voz lírica que é própria da tradição literária portuguesa, como se a sua obra residisse entre uma tradição e uma inovação.

A renda é constituída por linhas que formam buracos, mas não os preenchem, deixando sempre espaços a serem completados pelo leitor, no caso da leitura do texto pedrosino. Esses "buracos" fazem com que existam, no romance, mais dúvidas do que certezas e mais ausências do que presenças. Todos esses ditos caracterizam a linguagem tanto de Inês quanto de Lygia, cujos textos não se deixam desvendar por completo.

Esses buracos deixados pela linguagem seriam semelhantes ao "buraco vazio da relação de amor", como descreve Roland Barthes (2011, p. 39); o luto implica uma relação amorosa, ele é o que fica quando da partida do ser amado. A personagem Raíza, em certo sentido, gosta de evocar as memórias que lhe restaram do pai porque o rememorar do luto traz à menina uma espécie de acalento por permiti-la reviver o sentimento de amor pelo pai. 
No tocante a esse evocar de memórias, Barthes (1984), também se remetendo à perda de sua progenitora, comenta sobre o hábito comum de tentar reviver a presença do falecido por fotos, costume esse de que ele não gosta, assim como também dos sonhos que tem com a mãe porque em nenhum ela the aparece por inteiro. Há sempre algo deslocado que não a traz verdadeiramente, semelhante ao que ocorre à Raíza, que sonha com o falecido pai: "Em lugar de rosto ele tinha uma rosa mas o perfume era de hortelã. Chamou-me tão insistentemente, Raíza, Raíza! Que é que ele queria dizer? E por que não disse?" (TELLES, 1998, p. 36). Em seus sonhos, o pai aparece, quase sempre tentando Ihe dizer algo, porém estes dizeres nunca se concretizam, ficam transitando no limiar dos silêncios, tão frequentes na narrativa. É um personagem ausente, evocado apenas pelas vagas lembranças da filha, e que se limita ao silêncio.

Nesse enredo, a morte aparece também por meio do suicídio de André, suposto amante da mãe de Raíza, acontecimento que é comentado por Maura (2014, p. 99): "'el suicidio de un personaje quiebra el discurso y provoca un cambio de escenario. La muerte parece ser lo único auténticamente real [...]”. Se o mistério é uma marca da literatura lygiana, quando se trata da morte, tal marca se torna ainda mais atenuada; não há obviedade nem esclarecimentos no tratamento desse tema. "A diferencia del tratamiento que la muerte se ha dado en la literatura de otros autores brasileños, en Fagundes Telles no hay muerte, se aborda como un acontecimiento repleto de incertidumbre y misterio" (ESCRIBÀ; ZAPATERO, 2014, p. 140).

A linguagem lygiana, assim como toda linguagem literária, não dá ao leitor certezas. Relacionando essa discussão ao espaço literário, é interessante trazer à cena Blanchot, para o qual a linguagem que não fala, por si só já fala. Para o crítico, a linguagem "não é silenciosa porque, precisamente, o silêncio fala-se nela" (BLANCHOT, 1987, p. 45). Desse modo, a linguagem é destituída de poder e revela sua impotência por não conseguir dizer tudo. Não sendo disponível, prefere ficar no silêncio, e é justamente nesse que residem as condições de um possível entendimento.

No trecho que segue, o personagem pedrosino fala da difícil relação que teve com a mãe: "Eu dizia que a amava e visitava-a cada vez menos para não ver o que a casa já não era" (PEDROSA, 2003, p. 66). Após a saída dos filhos, a mãe ficou morando sozinha; a casa tornou-se habitada pelo silêncio. Era esse que preenchia o 
vago dos cômodos e do coração da mãe que fora, aos poucos, sendo abandonada pelos filhos.

Semelhante ao que ocorreu à mãe, é a relação entre os dois, homem e mulher que narram. Essa amizade se reduziu ao nada, ao que não houve, não foi dito e ao tempo em que ambos não mais existiam, isto é, o suposto presente em que tudo está sendo narrado, pois a amizade agora não mais existe de fato, já que cada um habita um espaço e um tempo diferentes: ele, o plano físico e tempo presente; ela, o plano metafísico e o tempo passado, conforme é expresso na citação:

A nossa morta amizade, vê tu - fotografia sem mancha. Sobrou dela tudo o que não dissemos. Tudo o que nos afastou, o tempo em que já não existíamos - nós. $E$ isso não morre - o que não existiu (PEDROSA, 2003, p. 86).

A impotência da linguagem faz com que as duas personagens do romance sejam impossibilitadas de se expressar por completo. Cada uma se expressa em cada capítulo, dizendo muito em palavras, mas, ao mesmo tempo, sem concluir e sem dizer nada por completo, deixando margens apenas para o vago. Não há uma comunicação efetiva porque o próprio contexto situacional não o permite: um vivo e uma morta falando sobre um passado incerto. Os silêncios, ou os buracos dessa renda de Inês Pedrosa, são preenchidos pela ausência de palavras; deseja-se tocá-las, porém, elas são inatingíveis, difíceis, não sendo permitido alcançá-las.

Tanto em Verão no aquário quanto em Fazes-me falta, é possível constatar um acurado trabalho com a linguagem literária. São textos que chegam ao leitor por meio de uma linguagem aparentemente sem nexo, mas que passa por um esmerilhamento. É como a metáfora empregada por Barthes (2004, p. 353), ao comparar o trabalho do escritor ao da costureira que faz um vestido: "pedaços são submetidos a ajustes". Esse modus operandi das escritoras não faz uma anarquia em suas obras, apenas mostra opções criativas no trato com a linguagem.

Para este estudo, considerou-se que a morte, e tudo o mais que vem com ela, como o luto, o sofrimento, as saudades... assemelha-se à escrita literária no sentido de que esta, também, é o espaço da dor. Em tudo aquilo que é dito nesses livros, e não em tudo o que é, percebem-se escritas de sofrimento deslindando personagens perseguidas por lembranças de seus mortos queridos e estas, ao invés de amenizar a dor sentida, fazem atenuar as distâncias físicas. 


\section{Considerações finais}

Conforme o estudo realizado, constatou-se que a linguagem no corpus escolhido é entrelaçada à temática da morte, presença esta que tece todo o halo de ausências/vazios nas narrativas. A linguagem trabalhada nos romances, assim como a morte de suas personagens, é lacunar. Esse caráter fúnebre alia elementos que estabelecem semelhanças entre morte e linguagem, como vazio, noite e silêncio.

Este trabalho apresentou um estudo dos romances Verão no aquário, de Lygia Fagundes Telles, e Fazes-me falta, de Inês Pedrosa, escritoras contemporâneas e com extensa contribuição para as literaturas brasileira e portuguesa, tendo como objeto a linguagem por meio da qual os textos são construídos. Após o contato com leituras de críticos que consideram a linguagem de ambas transgressora e lacunar e posterior constatação na leitura dos romances, percebeu-se que a análise das obras perspectivada pelo inusitado de sua construção é uma seara de possibilidades para estudo.

Há presenças constantes de símbolos, cuja busca do significado é deixada a critério do leitor, o que torna a leitura dos dois romances enigmática. Nas duas obras, é possível perceber a íntima relação que as escritoras constroem entre os vários temas que discutem por meio de uma linguagem vazia e obscura como a morte. As várias reflexões metalinguísticas presentes nos textos possibilitam entrever a preocupação que as autoras têm com o fazer literário ou com sua própria matériaprima: a escrita. É por meio desta que muitos leitores são atraídos a emaranhar-se nas teias das ficções de Inês Pedrosa e Lygia Fagundes Telles, situadas em cenários literários tão fecundos e aproximados, como são o português e o brasileiro.

Com base nisso, verificou-se que essa linguagem atua nos sentidos internos dos dois textos por meio de "buracos", estes infindos vazios que se juntam e compõem um tecido formado pela "presença da ausência", como o próprio Barthes (2011, p. 67) sugere.

Tais inferências foram realizadas com base em pesquisadores que compõem parte da fortuna crítica das autoras, assim como críticos e teóricos que trazem contribuições acerca dos modos de visualização da linguagem literária contemporânea, além, evidentemente, de pesquisa e reflexão no próprio texto literário.

Notou-se também que, ao longo do enredo dos romances, são suscitadas várias reflexões metaliterárias, dando margem para inferir que a literatura, ao falar 
sobre temáticas e contextos sociais diversos, também fala muito de si. É preciso, assim, ter sensibilidade aguçada para perceber o que há nos entremeios destas palavras que, aparentemente, só dizem sobre aspectos sociais, mas que, entre os "buracos de sua renda" dizem bastante a respeito daquilo que traz esse social até o leitor: a linguagem.

Espera-se que esse estudo venha suscitar reflexões em torno das múltiplas possibilidades ofertadas pelas obras de Lygia Fagundes Telles e Inês Pedrosa, especialmente com foco nas discussões que envolvem reflexões acerca da linguagem, contribuindo para o florescer de novas pesquisas voltadas à literatura, fator que muito aproxima os dois países, Brasil e Portugal.

\section{REFERÊNCIAS}

BARTHES, Roland. A câmara clara: nota sobre a fotografia. Trad. Júlio Castañon Guimarães. Rio de Janeiro: Nova Fronteira, 1984.

BARTHES, Roland. Diário de Luto - 26 de outubro 1977 - 15 de setembro de 1979. Trad. de Leyla Perrone-Moisés. São Paulo: Martins Fontes, 2011.

BARTHES, Roland. O rumor da língua. Trad. Mário Laranjeira. São Paulo: Martins Fontes, 2004.

BLANCHOT, Maurice. A literatura e o direito à morte. In.: A parte do fogo. Trad. Ana Maria Scherer. Rio de Janeiro: Rocco, 1997.

BLANCHOT, Maurice. O espaço literário. Trad. Álvaro Cabral. Rio de Janeiro: Rocco, 1987.

DELEUZE, Gilles. Crítica e Clínica. Trad. Peter Pál Pelbart. São Paulo: Ed. 34, 1997.

DELEUZE, Gilles; GUATTARI, Félix. Mil Platôs: capitalismo e esquizofrenia. Vol.1. São Paulo: Ed. 34, 2011.

ESCRIBÀ, Àlex Martín; ZAPATERO, Javier Sánchez. La novela negra y policiaca en Brasil: Lygia Fagundes Telles, entre el misterio y la fantasia. Releituras de Lygia Fagundes Telles / Ascensión Rivas Hernandez, Helena Bonito Pereira (org.). São Paulo: Editora Mackenzie e Ediciones Universidad de Salamanca, 2014.

GOMES, Carlos Magno. A circularidade da escrita de Lygia Fagundes Telles. Alea, Rio de Janeiro, v. 19, n. 3, p. 557-570, dez. 2017. Disponível em: http://www.scielo.br/scielo.php?script=sci_arttext\&pid=S1517- 
106X2017000300557\&Ing=pt\&nrm=iso. DOI: https://doi.org/10.1590/1517106x/2017193557570. Acesso em: 02 mar. 2020.

LAGUARDIA, Angela Maria Rodrigues. Fazes-me Falta, de Inês Pedrosa: uma alegoria contemporânea da "saudade". Dissertação (Mestrado em Letras) - Programa de Pós-Graduação em Letras: Estudos Literários, Universidade Federal de Minas Gerais. Belo Horizonte, p. 126. 2007.

LUCENA, Suênio Campos de. Sobre lembrar e esquecer em Lygia Fagundes Telles: Recorrências na sua ficção e memória recriada. Releituras de Lygia Fagundes Telles / Ascensión Rivas Hernandez, Helena Bonito Pereira (org.). São Paulo: Editora Mackenzie e Ediciones Universidad de Salamanca, 2014.

MAURA, Antonio. Una difusa imagen del espejo (las novelas de formación de Lygia Fagundes Telles). Releituras de Lygia Fagundes Telles / Ascensión Rivas Hernandez, Helena Bonito Pereira (org.). São Paulo: Editora Mackenzie e Ediciones Universidad de Salamanca, 2014.

NAVAS, Diana; VENTURA, Telma. A escrita feminina em azes-me falta: Corpo morto, corpo descontruído. Revista Desassossego, [S. I.], v. 9, n. 18, p. 85-100, 2018. DOI: 10.11606/issn.2175-3180.v9i18p85-100. Disponível em: https://www.revistas.usp.br/desassossego/article/view/131468. Acesso em: 20 nov. 2019.

PEDROSA, Inês. Fazes-me falta. São Paulo: Planeta, 2003.

RÉGIS, Sônia. A densidade do aparente. In: Cadernos de literatura brasileira: Lygia Fagundes Telles. № 5. São Paulo: Instituto Moreira Salles, março 1998.

TELLES, Lygia F. Verão no aquário. Rio de Janeiro: Rocco, 1998. 